\title{
An update on therapies for the treatment of diabetes-induced osteoporosis
}

\section{Sahar Mohsin, May MYH Baniyas, Reem SMH AIDarmaki, Kornélia Tekes, Huba Kalász \& Ernest A. Adeghate}

To cite this article: Sahar Mohsin, May MYH Baniyas, Reem SMH AIDarmaki, Kornélia Tekes, Huba Kalász \& Ernest A. Adeghate (2019): An update on therapies for the treatment of diabetes-induced osteoporosis, Expert Opinion on Biological Therapy, DOI: 10.1080/14712598.2019.1618266

To link to this article: https://doi.org/10.1080/14712598.2019.1618266

Accepted author version posted online: 11 May 2019.

Submit your article to this journal ¿

山 Article views: 3

View Crossmark data $₫$ 
Publisher: Taylor \& Francis

Journal: Expert Opinion on Biological Therapy

DOI: $10.1080 / 14712598.2019 .1618266$

An update on therapies for the treatment of diabetes-induced osteoporosis

Sahar Mohsin ${ }^{1}$, May MYH Baniyas ${ }^{1}$, Reem SMH AlDarmaki ${ }^{1}$, Kornélia Tekes ${ }^{2}$, Huba Kalász ${ }^{3}$, Ernest A. Adeghate ${ }^{1 *}$

Affiliations:

1Department of Anatomy, College of Medicine \& Health Sciences, United Arab Emirates University, Al Ain, United Arab Emirates

2Department of Pharmacodynamics, Faculty of Pharmacy, Semmelweis University, Budapest, Hungary

3Department of Pharmacology and Pharmacotherapy, Faculty of Medicine, Semmelweis University, Budapest, Hungary

Short title: Running title: Therapy for diabetes-induced osteoporosis

*Address correspondence to:

Professor Ernest A. Adeghate

Department of Anatomy

College of Medicine \& Health Sciences,

United Arab Emirates University,

P.O. Box 17666, Al Ain,

United Arab Emirates

e-mail: eadeghate@uaeu.ac.ae 
Short title: Running title: Therapy for diabetes-induced osteoporosis

Abstract
Introduction: Currently, 424 million people aged between $20-79$ years worldwide are diabetic More than $25 \%$ of adults aged over 65 years in North America have Type 2 diabetes mellitus (DM). Diabetes-induced osteoporosis (DM-OS) is caused by chronic hyperglycemia, advanced glycated end products and oxidative stress. The increase in the prevalence of DM-OS has prompted researchers to develop new biological therapies for the management of DM-OS.

Areas covered: This review covered the current and novel biological agents used in the management of DM-OS. Data were retrieved from PubMed, Scopus, American Diabetes Association and International Osteoporosis Foundation websites, and ClinicalTrials.gov. The keywords for the search included: DM, osteoporosis, and management.

Expert opinion: Several biological molecules have been examined in order to find efficient drugs for the treatment of DM-OS. These biological agents include anti-osteoporosis drugs: net anabolics (parathyroid hormone/analogues, androgens, calcilytics, anti-sclerostin antibody), net anti-resorptive osteoporosis drugs (calcitonin, estrogen, selective estrogen receptor modulators, bisphosphonates, RANKL antibody) and anti-diabetic drugs (alpha glucosidase inhibitors, sulfonylureas, biguanides, meglitinides, thiazolidinediones, GLP-1 receptor agonists, dipeptidylpeptidase-4 inhibitors, sodium glucose co-transporter-2 inhibitors, insulin). Biological 
medications that effectively decrease hyperglycemia and, at the same time, maintain bone health would be an ideal drug/drug combination for the treatment of DM-OS.

Key words: Diabetes-induced osteoporosis, anti-diabetic drugs, bone mineral density, bone, hormones, anti-osteoporosis drugs 


\section{Article highlights}

- Osteoporosis is a common, chronic metabolic disease affecting more than 200 million people world wide

- Osteoporosis is 4-5 times higher in people with diabetes mellitus (DM) compared to nondiabetic people

- The financial burden of osteoporosis-induced fractures was $\$ 17$ billion in 2005 , in the USA. This amount is expected to double within the next 20 years.

- Risk factors for diabetes-induced osteoporosis include genetic predisposition, age $>50$ years, a sedentary lifestyle, smoking, chronic alcohol consumption, use of medications such as corticosteroids and proton pump inhibitors.

- Optimal glycemic control is key to preventing and managing diabetes-induced osteoporosis

- The safest hypoglycemic drugs in diabetic patients suffering from osteoporosis include, metformin and GLP-1 receptor agonists. The most beneficial drugs against osteoporosis in DM patients are bisphosphonates, androgens and receptor activator of nuclear factor kappa-B ligand 


\section{Abbreviations}

Alpha- 1 coll $=$ alpha- 1 collagen

$\mathrm{AGE}=$ Advanced glycated end products

$\mathrm{Akt}=$ Protein kinase $\mathrm{B}$

ALP $=$ Alkaline phosphatase

ATP $=$ Adenosine triphosphate

$\mathrm{BMD}=$ Bone mineral density

$\mathrm{DM}=$ Diabetes mellitus

DM-OS $=$ Diabetes-induced osteoporosis

DPP-4 = Dipeptidyl peptidase 4

FDA $=$ Food and Drug Administration

GLP-1 = Glucagon like peptide-1

HbAlc $=$ Glycated hemoglobin

IGT $=$ Impaired glucose tolerance

AMPK $=$ Adenosine monophosphate-activated protein kinase

PI3 = Phosphoinositol 3 kinase

PPAR- $\gamma=$ Peroxisome proliferator-activated receptor gamma

$\mathrm{PTH}=$ Parathyroid hormone

PTHrP = Parathyroid hormone-related protein

RAGE $=$ Advanced glycated end products receptor

RANKL $=$ Receptor activator of nuclear factor kappa-B ligand

ROS $=$ Reactive oxygen species

RUNX2 $=$ Runt-related transcription factor 2

SERM $=$ Selective estrogen receptor modulators

SGLT2 $=$ Sodium glucose co-transporter 2

$\mathrm{T} 1 \mathrm{DM}=$ Type 1 diabetes mellitus

$\mathrm{T} 2 \mathrm{DM}=$ Type 2 diabetes mellitus

$\mathrm{TC}=$ Total cholesterol

$\mathrm{UV}=$ Ultraviolet

VLDL $=$ Very low density lipoprotein

ERK $=$ Extracellular-signal-regulated kinases

$\mathrm{Wnt}=$ Wingless/Integrate 


\section{Introduction}

\subsection{Diabetes mellitus and osteoporosis}

Diabetes mellitus (DM) is a common and chronic endocrine disease prevalent in all regions of the globe. It is, however, more common among urban dwellers compared to those living in rural and suburban areas [1]. DM is characterized by hyperglycemia, polyuria, polydipsia and polyphagia. DM consists of two major types, type 1 (T1DM) and type 2 (T2DM). T1DM is caused by a selective immune destruction of pancreatic beta cells [2], leading to significant loss in blood insulin. The serum of patients suffering from T1DM may contain antibodies against pancreatic beta cells or their cellular components $[1,2]$. In contrast, T2DM is common amongst adult and senior members of the population and accounts for about $90 \%$ of people with DM [1]. T2DM was previously called non-insulin-dependent DM [3], because the patient still has DM irrespective of the fact that the insulin level may in fact be normal or even higher. The patient has chronic hyperglycemia, a key sign for the diagnosis of DM. It is similar to a case of "poverty in the midst of plenty". The patient has a high concentration of glucose in the blood that is not taken up by either, fat, muscle or liver cell, because of insulin resistance, which means that the action of insulin molecule is compromised. Insulin resistance may be caused by a defect in either the insulin or GLUT4 receptor molecule [4] or a combination of both. The postprandial increase in insulin seen after a meal [5] fails to bring blood glucose level down several hours afterwards, resulting in sustained hyperglycemia. Other types of DM include gestational diabetes (GDM), a variant of glucose intolerance seen in pregnant women [6]. GDM is said to be induced by increase in the level of several hormones seen after the onset of pregnancy. Increase in the level of growth hormone, human placental lactogen, progesterone, estrogen and other hormones that increase during pregnancy appears to grossly impair the metabolism of insulin and glucose [6], leading to hyperglycemia. Any of these types of DM may be associated with osteoporosis, a 
condition where bone becomes porous because it has lost bone components, failed to make enough bone tissue or a combination of both. In fact, many reports have shown that DM is associated with abnormal bone formation leading to bone fragility and poor strength $[7,8]$. In addition to DM several other factors can lead to the development of osteoporosis. These include low levels of estrogen and androgen; hormonal disease such as Cushing syndrome, hyperparathyroidism, and hyperthyroidism [9]. Genetic diseases (aromatase deficiency, mutations, Marfan syndrome, homocystinuria, Ehlers-Danlos syndrome) affecting the metabolism of type 1 collagen may also result in the development of osteoporosis [9]. Moreover, increasing age, alcohol intake, heavy smoking, inadequate sun exposure, diet deficient in calcium, small body weight may also predispose individuals to osteoporosis. Out of all of these parameters, ageing is a key and predominant risk factor for the development of osteoporosis [1015]. Body weight, obesity or cachexia influence how skeletal bone responds to remodeling [16]. This means that individuals with small body weight are at risk of developing osteoporosis compared to those with heavier body weight [17]. In addition to these risk factors, genetic studies showed that skeletal geometry, BMD and metabolism of bone turnover could be inherited [18]. The factors regulating these genetic manifestations in bone have not been clearly elucidated [18] but mutations of genes that regulate the metabolism of different components of bone have been implicated [20].

Drugs used in the treatment of other diseases including but not limited to hypertension, epilepsy, multiple myeloma, and other malignancies have the tendency to induce osteoporosis. Other medications like vitamins A and D, heparin may also cause osteoporosis, especially when used in very high doses [9]. Table 1.

Table 1: Factors that increase the risk of developing osteoporosis 


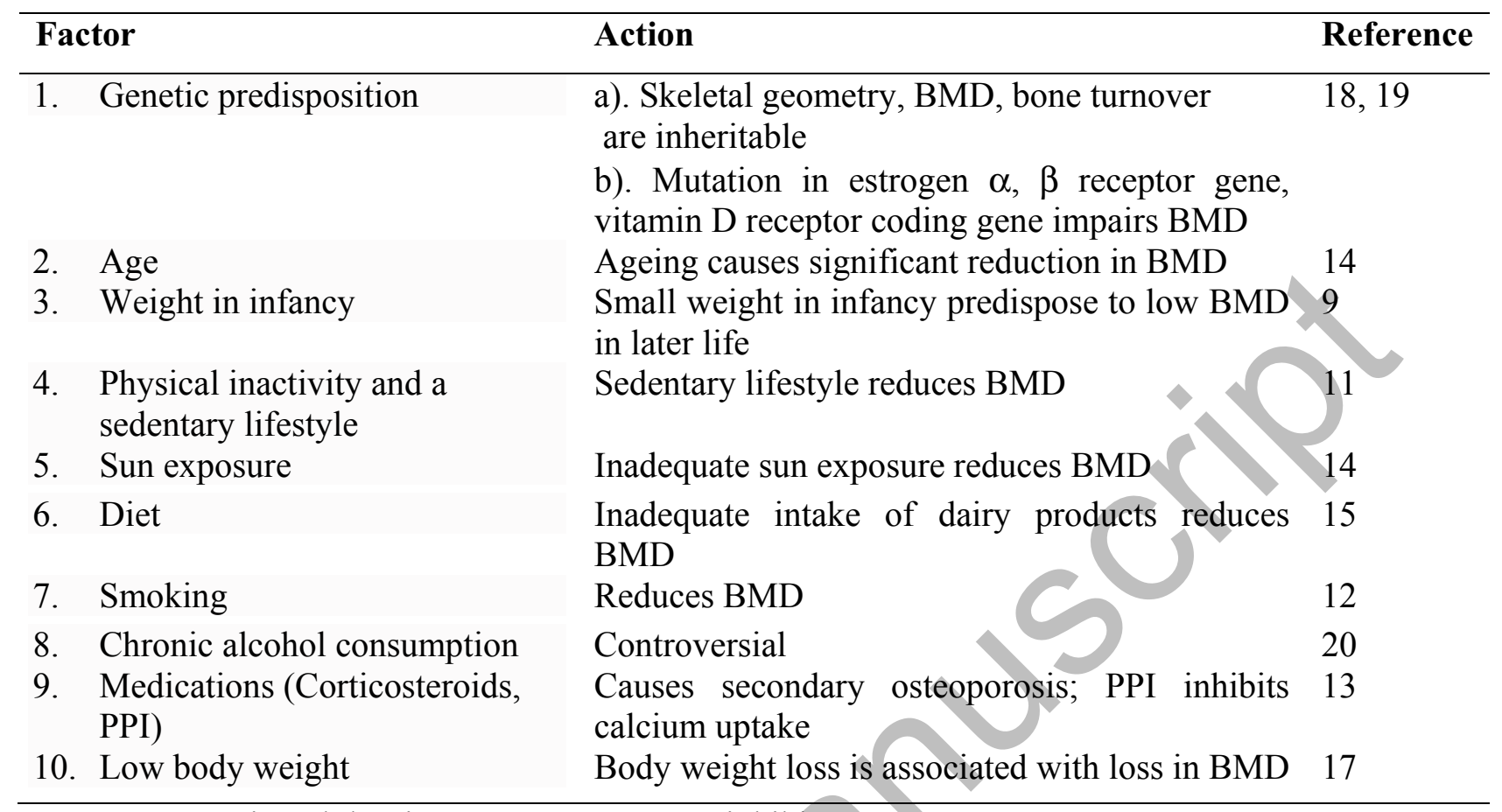

$\mathrm{BMD}=$ Bone mineral density; PPI=Proton pump inhibitors

\subsection{Epidemiology of diabetes mellitus and osteoporosis}

1.2.1. Diabetes mellitus: According to the 2017 International Diabetes Federation report, 424.9 million people aged 20-79 years worldwide have DM. This accounts for about $8.8 \%$ of the world population of 4.84 billion in this age group [21]. This percentage is much higher (11.3\%) in older age group. The number of diabetic patients is estimated to reach 626.6 million in 2045 , making up of more than $9.9 \%$ of the total world population amongst people aged $20-79$ years. The number of people with impaired glucose tolerance (IGT) is equally high. In $2017,7.3 \%$ of the world's population between 20-79 years of age has a form of IGT. This number is projected to reach $8.3 \%$ by the year 2045 [21]. In the USA for example, the prevalence of DM is put at $9.3 \%$ of the population with an additional $28 \%$ in the pre-diabetes stage [22]. This observation is particularly true for the Middle East and North Africa region and Micronesia were the prevalence of DM is way over $12.0 \%$ of the population [21]. The reason for the increase in the prevalence of 
DM in these developing regions has been attributed to the adoption of Western diet, life style and reduced physical activity. Paul Zimmet referred to this phenomenon as "coca-colonization" in 2000 [23]. All of these reports show that the health risks posed by DM including diabetesinduced osteoporosis will continue to grow.

1.2.2. Osteoporosis: When compared to DM, osteoporosis is also a common metabolic disease that currently affects more than 200 million people globally. It is more common in women compared to men and its prevalence increases as we age. For example, approximately, one out two women over the age of 90 years will have osteoporosis [24]. 37\% of the total number of osteoporosis patients resides in Europe, USA and Japan [25], however, projected increase in the prevalence of osteoporosis have been reported in several regions of the world including Asia, Middle East and Africa. In fact, it is estimated that by the year 2050, Asia will account for $50 \%$ of all worldwide hip fractures due to osteoporosis [26]. This is because osteoporosis is significantly underreported and undertreated in major Asian countries including China and India, where a large percentage of the population live in rural areas [27]. Improvement in healthcare delivery in the future will allow more people, especially those in rural areas, with osteoporosis to be diagnosed.

The trajectory of the epidemiology of DM is similar to that of osteoporosis. The projected increase in the number of people with diabetes will most likely contribute to the increase in the number of patients with diabetes-induced osteoporosis.

\section{Diabetes-induced osteoporosis}


Micro- and macro-angiopathy, neuropathy coupled with increased formation of advanced glycated end (AGE) product [28] prevent optimal blood flow and impair the overall structure and function of bone. Reports have shown that T1DM is associated with a reduced bone mineral density (BMD) that predisposes to an increased risk of bone fracture [10]. In fact, a study conducted in a Middle East country showed that $46 \%$ of postmenopausal women suffering from DM has osteoporosis [29].

It is worth noting, however, that BMD differs in T1DM compared to T2DM. In contrast to T2DM, T1DM is associated with a reduced BMD [30]. T1DM-induced reduction in BMD is partly due to early onset of diabetes, reduced formation of bone [31], probably due to poor development. In spite of the chronic hyperglycemia, most studies reported that patients with T2DM have paradoxically displayed increased BMD [30]. The increased BMD in T2DM patients has been attributed to the high BMI seen in these patients. High BMI is an important feature in patients with T2DM [32]. In spite of the high BMD in T2DM, bone fractures are equally common compared to T1DM because of bone fragility and micro-cracks [33] resulting from micro-vascular complications.

\subsection{Mechanism of diabetes-induced osteoporosis}

DM is associated with chronic elevation in plasma blood glucose. Persistent high blood glucose induces oxidative stress and toxicity that destroys the few remaining viable pancreatic beta cells, leading to a further deterioration of DM [28]. Chronic hyperglycemia causes severe impairment in lipid, carbohydrate and protein metabolism. Disruption in lipid metabolism results in increased level of very low density lipoprotein (VLDL) and total cholesterol (TC) [34], resulting in the accumulation of VLDL and TC in sub-endothelial and endothelial cell layers. Chronic 
accumulation of fat will result in atherosclerosis and narrowing of vascular lumen. Impaired vascular structure and function affect blood flow to a large variety of organs including but not limited to bone, retina, kidney, neurons of the central and peripheral nervous systems, many other vital tissues and organs such as heart [28]. Continued, and long-term deposition of VLDL in the sub-endothelial layer of blood vessels may lead to the development of micro- and macroangiopathy [28] resulting in poor blood supply to bone. Bone tissue will not be functioning properly if the vasculature is poor and may develop structural anomalies such as micro-cracks. Another factor that may also contribute to the development of diabetic complications is hyperglycemia-induced oxidative stress. Oxidative stress facilitates the release of reactive oxygen species (ROS) such as hydroxyl radicals, superoxides, peroxides, alpha- and singletoxygen [35]. It is well known that chronic hyperglycemia stimulates the formation of advanced glycated end products [28], which in turn cause structural changes in molecules involved in the formation of type 1 collagen and other biological factors responsible for bone integrity. In fact, it has been shown that pentosidine, an AGE product causes non-enzymatic glycation of type 1 collagen cross-links resulting in impaired bone mass formation [36]. Several studies have shown that receptors for AGE products (RAGE) prevent the proliferation of osteoblasts via inhibition of a variety of signaling pathways including PI3, ERK and Wnt [37]. Moreover, RAGE has been shown to increase the formation of osteoclasts [38] leading defective bone formation. The ability of AGE products to polymerize after binding to RAGE causes cross-linkages in skeletal proteins resulting in bone stiffness and fragility [39]. All of these AGE-induced changes may result in deranged biomechanical parameters of bone. DM also appears to affect total protein content of tissues of which collagen is a member. A marked decrease in the protein content was measured in the pancreas, parotid, submandibular and lacrimal glands after the onset of DM [40]. Previous 
studies have shown that DM caused a significant reduction in pancreatic amylase [41]. In a similar pattern, crucial enzymes, such as alkaline phosphatase, implicated in the formation of bone are reduced after the onset of DM [42]. Recent studies have shown that plasminogen activator inhibitor-1 (PAI-1) may play a role in the pathogenesis of osteoporosis because PAI deficiency reduces bone loss in experimental animals by inhibiting osteoclast activity and modulating alkaline phosphates function [43]. PAI-1 was significantly reduced in T2DM patients with osteoporosis when compared to T2DM patients without osteoporosis [44]. Osteocalcin, a hormone produced by osteoblast that has been reported to stimulate insulin release and mineralization of bone [45], may also play a role in the pathogenesis of DM-OS.

A combination of lipid deposition, poor blood supply, glucose toxicity coupled with oxidative stress may lead to the development of osteoporosis.

\subsection{Effect of diabetes-induced osteoporosis on patients' quality of life}

$\mathrm{DM}$ is associated with high mortality and morbidity if not treated. The reason for this is that DM causes multi-organ disease and complications that may severely impair vision, cardiac and kidney functions, and the musculoskeletal system. The addition of osteoporosis puts extra burden on a patient with all of the unpleasant morbidities associated with DM. Osteoporosis by itself puts tremendous burden on the patient. The personal and economic burden placed on diabetesinduced osteoporotic patient, if not well managed, is far more severe that those seen in patients suffering from malignant disease or even bronchial asthma [46]. The chances of an osteoporosis patient of having another bone fracture, after a previous one is more than $86 \%$ [47]. Bone fracture risk is a major health issue in patients with DM-induced osteoporosis because many of the key hypoglycemic agents, such as insulin, sulfonylureas, sodium-glucose cotransporter-2 inhibitors increase the risk of hypoglycemia, a major cause of fall, and subsequently, fracture 
especially in elderly patients. It is thus, extremely important to select the right hypoglycemic drugs for this group of patients. The number of days spent in health care facilities by DM-OS patient has been shown to be significantly higher when compared to other chronic, noninfectious diseases such as DM alone or cancer of the breast [48].

\section{Management of patients with diabetes-induced osteoporosis}

Since osteoporosis is a consequence of net bone loss and/or abnormal microarchitecture due to the derangement in the delicate harmony between bone formation and reabsorption, most management regimens look at factors that would either, increase net bone formation, reduce net bone resorption or repair abnormal structure [49]. Medication that increases net bone formation [e.g. parathyroid hormone, abaloparatide (PTHrP-1-34 analogue)] will increase bone mineral density (BMD), while net anti-resorptive drugs (e.g. calcitonin, denosumab, oestrogen, selective estrogen receptor modulators, bisphosphonates, strontium ranelate) prevent degradation of components of bone. Other types of treatment include the administration of calcium and vitamin D to facilitate optimal mineralization of bone [49]. Lifestyle modification (physical activity, diet) is crucial to maintaining an optimal bone health. Physical activity significantly reduces the risk of developing osteoporosis by increasing osteogenesis and bone formation via mechanosignaling and mechano-transduction processes [50]. Drugs and life style modifications employed in the management of osteoporosis should be ideally beneficial to a DM patient (Tables 2, 3).

Table 2: Non-therapeutic management of diabetes-induced osteoporosis 


\begin{tabular}{|c|c|c|c|}
\hline Factor & Action on bone health & Effect on DM & Reference \\
\hline 1. Sunshine & $\begin{array}{l}\text { 7-dehydrocholesterol is } \\
\text { converted to vitamin D3 in the } \\
\text { skin by UV light }\end{array}$ & See Vitamin D & 51 \\
\hline 2. High protein diet & $\begin{array}{l}\text { Provides necessary amino acid } \\
\text { pool for the synthesis of bone } \\
\text { matrix proteins. Maintains BMD }\end{array}$ & $\begin{array}{l}\text { No specific positive } \\
\text { or negative effect }\end{array}$ & 52 \\
\hline $\begin{array}{l}\text { 3. High vegetable and fruit } \\
\text { diet }\end{array}$ & $\begin{array}{l}\text { Possibly via antioxidant content } \\
\text { of fruits and vegetables }\end{array}$ & Reduces DI & \\
\hline 4. Exercise & $\begin{array}{l}\text { Increases osteogenesis and bone } \\
\text { growth }\end{array}$ & $\begin{array}{l}\text { Improves } \\
\text { control }\end{array}$ & \\
\hline 5. Vitamin D & $\begin{array}{l}\text { Improves bone health through } \\
\mathrm{Ca}^{2+} \text { mobilization }\end{array}$ & $\begin{array}{l}\text { Reduces } \mathrm{HbAlc} \text { and } \\
\text { fasting blood glucose }\end{array}$ & 55 \\
\hline 6. Calcium rich diet & Improves bone health & No specific effect & 16 \\
\hline 7. Minerals (e.g. $\mathrm{K}^{+}, \mathrm{Mg}^{2+}$ ) & $\begin{array}{l}\text { Maintain BMD via alkaline- } \\
\text { producing moiety }\end{array}$ & $\begin{array}{l}\mathrm{Mg}^{2+} \text { delays onset of } \\
\mathrm{DM}\end{array}$ & 56 \\
\hline
\end{tabular}

Table 3A: Potential drugs with net anabolic properties (target cell: osteoblast) for the treatment of diabetes-induced osteoporosis

\begin{tabular}{|c|c|c|c|}
\hline Factor & Action & Effect on DM & Reference \\
\hline $\begin{array}{l}\text { 1. Parathyroid hormone } \\
{[\text { rhPTH }(1-34, \text { PTH }(1-84)]} \\
\text { (teriparatide, abaloparatide } \\
\text { and analogues }\end{array}$ & $\begin{array}{l}\text { PTH stimulate osteoblast to } \\
\text { deposit osteoid and } \\
\text { significantly increase BMD; } \\
\text { also increases bone resorption }\end{array}$ & $\begin{array}{l}\text { Controversial. } \\
\text { Induces } \\
\text { hyperglycemia, } \\
\text { Reduces insulin } \\
\text { sensitivity }\end{array}$ & $\begin{array}{l}57,58,59 \\
60,61\end{array}$ \\
\hline 2. Androgens & $\begin{array}{l}\text { Increase BMD in childhood } \\
\text { osteoporosis }\end{array}$ & $\begin{array}{l}\text { Low dose inhibits } \\
\text { while high dose } \\
\text { increases insulin } \\
\text { sensitivity }\end{array}$ & 62,63 \\
\hline 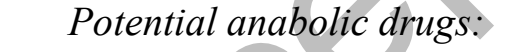 & & & \\
\hline 3. Calcilytics (e.g. NPS & $\begin{array}{l}\text { Reduce calcium-sensing } \\
\text { receptor, thereby increasing } \\
\text { the pool of PTH }\end{array}$ & See PTH & 64 \\
\hline $\begin{array}{l}\text { 4. Anti-sclerostin antibody } \\
\text { (Romosozumab } \\
\text { Approved in Japan but not } \\
\text { yet in USA) }\end{array}$ & $\begin{array}{l}\text { Blocks sclerostin, improves } \\
\text { osteoblast function via Wnt/ } \beta \text { - } \\
\text { catenin pathway }\end{array}$ & None reported & 65,66 \\
\hline 5. Osteocalcin & $\begin{array}{l}\text { Stimulates osteoblast } \\
\text { proliferation via AMPK }\end{array}$ & $\begin{array}{l}\text { Improves glucose } \\
\text { metabolism }\end{array}$ & 67 \\
\hline
\end{tabular}


Table 3B: Potential drugs that prevent net resorption of bone (target cell: Osteoclast) for the treatment of diabetes-induced osteoporosis

\begin{tabular}{|c|c|c|c|}
\hline Factor & Action & Effect on DM & Reference \\
\hline 1. Calcitonin & Reduces bone resorption & Controversial & 68,69 \\
\hline 2. Estrogen & $\begin{array}{l}\text { Inhibits osteoclast } \\
\text { differentiation, blocks sclerostin }\end{array}$ & $\begin{array}{c}\text { Increases the risk } \\
\text { of developing } \\
\text { DM }\end{array}$ & \\
\hline $\begin{array}{l}\text { 3. Selective estrogen } \\
\text { receptor modulators } \\
\text { (tamoxifen, raloxifene) }\end{array}$ & $\begin{array}{l}\text { Inhibits osteoclasts } \\
\text { differentiation, Blocks } \\
\text { sclerostin }\end{array}$ & Neutral & \\
\hline 4. Strontium ranelate & Withdrawn from market & & \\
\hline $\begin{array}{l}\text { 5. Bisphosphonates } \\
\text { (zoledronic acid, } \\
\text { alendronate, risedronate, } \\
\text { ibandronate) }\end{array}$ & $\begin{array}{l}\text { Significantly inhibits osteoclast } \\
\text { activity }\end{array}$ & $\begin{array}{l}\text { Significant } \\
\text { reduction in DM }\end{array}$ & $\begin{array}{c}71,72,73, \\
74\end{array}$ \\
\hline $\begin{array}{l}\text { 6. RANKL antibody } \\
\text { (Denosumab) }\end{array}$ & $\begin{array}{l}\text { Inhibits the formation, } \\
\text { development \& differentiation } \\
\text { of osteoclasts }\end{array}$ & $\begin{array}{l}\text { Improves insulin } \\
\text { sensitivity and } \\
\text { glucose } \\
\text { metabolism }\end{array}$ & $\begin{array}{c}75 \\
76,77\end{array}$ \\
\hline 7. Cathepsin K inhibitors & $\begin{array}{l}\text { Block the ability of osteoclasts } \\
\text { to degrade bone matrix }\end{array}$ & Unknown & 78 \\
\hline 8. Calcium & Improve both health & $\begin{array}{l}\text { No specific } \\
\text { effect }\end{array}$ & 16 \\
\hline
\end{tabular}

\subsection{Osteoporotic drugs with anabolic properties}

3.1.1. Parathyroid hormone (PTH) stimulates osteoblasts to deposit osteoid resulting in new bone formation [57]. Recombinant version of PTH (hPTH-(1-34) was approved by the Food and Drug Administration (FDA) in 2002 and marketed as teriparatide. It is a potent anabolic drug for the treatment of osteoporosis because it significantly increases BMD [58], and bone size. Attempts to produce and market analogues (ostabolin-C) of PTH did not materialize. Ostabolin-C was withdrawn by Zelos Pharmaceutical in 2009 [59]. However, abaloparatide, a PTH protein analogue, was approved by the Food and Drug Administration (USA) in April 2017. Abalopartide has antioxidant properties and capable of stimulating chondrogenesis and reducing vertebral and non-vertebral fractures 
by $86 \%$ and $43 \%$, respectively in older women suffering from osteoporosis [79]. What then is the impact of PTH on glucose homeostasis? It was reported, from a study involving 1,175 patients with type $2 \mathrm{DM}$, that higher levels of PTH are associated with lower level of fasting blood glucose and $\mathrm{HbA} 1 \mathrm{c}$ [80]. In contrast, some reports show that $8 \%$ of patients with primary hyperparathyroidism have DM when compared to the general population [81]. Recent reports showed that high concentrations of PTH are associated with hyperglycemia in a study of elderly pre-diabetic patients [60]. Reduced insulin sensitivity has also been reported in pregnant women with high PTH level [61]. Until more definite studies have been performed to assess the effect of PTH on diabetes, prescription of PTH analogs should therefore be done with care in diabetes-induced osteoporosis.

3.1.2. Androgens such as testosterone have been suggested for the treatment of childhood osteoporosis [62]. However, the impact of androgens on childhood DM is unknown. In contrast, clinical studies performed in adult population showed that low testosterone level predispose patients to DM [82], while high levels of testosterone increases insulin sensitivity [63]

3.1.3. Calcilytics increase the pool of PTH by inhibiting the activity of calcium sensing receptors [64]. In addition, biological molecules that block sclerostin, a protein secreted by osteocyte, would have an anabolic effect on bone because sclerostin has a negative effect on osteoblasts [65]. 
3.1.4. Anti-sclerostin monoclonal antibody has been produced by Amgen Inc (Thousand Oaks, CA, USA) with a generic name of romosozumab and trade name of Evenity®. Romosozumab improves osteoblast function via the Wnt/catenin signaling pathway resulting in increased BMD [83]. The effect, if any, of these relatively new agents (romosozumab), on glucose metabolism remains unclear.

3.1.5. Osteocalcin is produced by osteoblasts and can enhance osteoblast differentiation through the activation of AMPK. AMPK is a strong antioxidant capable of preventing apoptotic degeneration of osteocytes. The ability of the molecule to sensor energy makes it a good candidate for the regulation of glucose metabolism [67]. The linking of osteocalcin, expressed in osteoblast, to glucose metabolism has created a new concept of bone-glucose axis. Table $3 \mathrm{~A}$.

\subsection{Agents that prevent net resorption of bone}

3.2.1. Calcitonin is secreted by the C cells of thyroid gland and prevents bone resorption coupled with a reduction in serum and urinary $\mathrm{Ca}^{2+}$ level. However, calcitonin, although approved by the FDA is not widely used because of its relatively low efficacy and tendency to cause cancer [68]. Studies performed on laboratory animals showed that deletion of calcitonin inhibits hyperglycemia in mice [69]. Moreover, another investigation indicated that salmon calcitonin increases insulin sensitivity and prevents hyperglycemia when applied orally [84]. In contrast, clinical studies involving a relatively few number patients showed that calcitonin induced hyperglycemia after acute but not chronic administration [85]. 
3.2.2. Estrogens can be used to prevent and treat osteoporosis. However, because of the risk of cancer, very low doses have been introduced either alone or in combination with other medications used in the treatment of osteoporosis [68]. Reports on the effect of estrogen on the risks of developing DM has continued to be controversial but many clinical studies point to increased risk of DM in postmenopausal women taking estrogens [70]. Table 3B.

3.2.3. Selective estrogen receptor modulators (SERM) such as tamoxifen and raloxifene have been approved for the treatment and prevention of osteoporosis. In spite of improving BMD, its major side effect is thromboembolism [86]. Most studies report that the effect of SERM on glucose metabolism is neutral [87]. Table 3B.

3.2.4. Bisphosphonates (zoledronic acid, alendronate, risedronate, ibandronate) have been known to have anti-osteoporosis effect for last 40 years [71]. They are widely used because of their efficacy. Bisphosphonate reduces vertebral and hip fractures by more than $50 \%$ [72]. They prevent bone resorption by inhibiting osteoclast activity. Inhibition of osteoclast function is done via blocking of farnesyl pyrophosphate synthase [71]. More than $50 \%$ reduction in the risk of developing T2DM was observed in a large retrospective study involving about 36,000 non-DM subjects (aged 60 years and over) taking bisphosphonates for osteoporosis [73]. This observation was supported by reports from Yang et al., [74].

Potentially, anti-resorptive drugs such as alendronate would increase the already normal or higher BMD seen in T2DM patients. However, studies have shown that bisphosphonates are indeed effective in the reduction of risks to skeletal bone fracture in postmenopausal T2DM patients [88]. Although, bisphosphonates may increase BMD, they have been shown to increase bone strength [89] and osteocyte life cycle [90]. These advantages of bisphosphonates may 
outweigh the risk of a putative increase in BMD. Although, bisphosphonates maintain the quality of existing $\mathrm{BMD}$, and prevent bone from becoming brittle and fragile, in the short term, in contrast long-term ( 2-3 years) use of bisphosphonates causes bone to become brittle [91]. Bisphosphonates have also been reported to cause osteonecrosis of the mandible [68]. It is worth noting that strontium ranelate, regarded as a dual agent for bone (facilitates osteoblast function and prevent osteoclast-induced bone resorption) has been taken off the market recently in Europe because of the risk of myocardial infarction [92]. Table 3B.

3.2.5. Calcium, a component of hydroxyapatite, is crucial for bone health. Insufficient calcium intake has been associated with risks of bone fracture [93], however, the benefit of calcium supplements still remains controversial. Larger studies appear to confirm the beneficial effect of calcium supplement in the reduction associated to bone fracture [93, 94]. Dietary intake of calcium is preferred to supplements because of the danger of complications associated with high serum level of calcium [93].

3.2.6. Receptor activator of nuclear factor kappa-B ligand (RANKL) is required for the maturation, development and differentiation of osteoclasts. Antibody against this molecule will therefore block osteoclast activity. Denosumab (RANKL antibody) has therefore been developed to treat osteoporosis with an efficacy as high as $68 \%$ [75]. Significant insulin sensitivity and normalization of blood glucose was observed when RANKL was blocked in both genetic and nutritional rodent models of T2DM [76]. In a study of 48 osteoporotic postmenopausal women treated with Denosumab, no changes were observed in blood glucose, insulin and insulin resistance levels, 24 weeks after treatment [77]. Table 3B. 
3.2.7. Cathepsin $K$ is a cysteine protease used by osteoclasts to degrade the organic components of bone matrix, including collagen. Therefore, inhibiting this enzyme will help in the prevention of bone resorption by osteoclasts. Phase III clinical trials of odanacatib, a cathepsin K inhibitor, show high efficacy in the treatment of osteoporosis. However, the trial and filing for FDA approval was terminated in 2016 because of high risk of stroke [78].

\subsection{Potential pharmacotherapies for diabetes in patients with osteoporosis}

Biological therapy for the treatment of diabetes-induced osteoporosis would require a doublepronged approach since the osteoporosis in question develops on the background of DM. This means that DM should also be treated and brought under control, using anti-diabetic drugs that prevent further deterioration of bone health and osteoporosis in particular.

Hypoglycemic drugs used in the treatment of diabetes-induced osteoporosis must be able to lower blood glucose level and prevent further development of acute and chronic complications of DM. These medications should in no way cause any harmful effect on bone metabolism. In fact, an ideal drug is one that has both hypoglycemic and bone repairing effects. Drugs or biological agents that increase the level of osteocalcin, an osteoblast-derived molecule, could potentially be an ideal drug because it stimulates osteoblast proliferation and improves insulin sensitivity [67].

3.3.1. Alpha glucosidase inhibitors: This group of oral anti-diabetic drugs, which includes, acarbose, miglitol and voglibose, prevents the conversion of ingested carbohydrate to monosaccharide by competitive inhibition of alpha glucosidase enzymes resident in the brush border of enteric cells of the gut [95]. It thus reduces hyperglycemia by preventive absorption of glucose into the circulation. In addition, alpha glucosidase inhibitors have been shown to 
stimulate GLP-1 release from the L-cells of the gut [96]. Either the beneficial or harmful effect of alpha glucosidase inhibitors, voglibose, on bone health has not been clearly documented [97]. In a large, nationwide study involving more that 2.89 million patients using anti-diabetic drugs, no major risks was attributed to patients taking alpha glucosidase inhibitors [98]. The side effects of voglibose on bone health have not been documented [99]. Table 4.

3.3.2. Sulfonylureas (SUs) (e.g. glipizide): A widely used anti-diabetic drug that facilitates insulin release from pancreatic beta cells via inhibition of potassium channels [95] has been reported to preserve and enhance the structure and function of osteoblast through a variety of pathways including the phosphoinositol 3 (PI3) kinase/Akt pathways [100]. The ability of sulfonylurea to maintain osteoblast structure and function is probably via insulin, a strong anabolic hormone. In contrast, some reports point to increased risk of hip fracture in elderly patients taking sulfonylureas [101]. The increase in hip fracture risk observed in elderly patients taking SUs may be due to the ability of SUs to cause hypoglycemia, a condition that could increase the risk of fall especially in the elderly population. In a recent review of the effect of anti-diabetic drugs on the musculoskeletal system, Kalaitzoglou et al [97] reported that the current clinical evidence do not support the classification of sulfonylureas (SUs) as been either harmful or beneficial to bone architecture. In fact they may be neutral or even beneficial when used as monotherapy. Since hypoglycemia is a common side effect of SUs, care should be taken when prescribing SUs to elderly patients with poor vision who are at risks of falling [97]. Table 4. 
3.3.3. Biguanides (e.g. metformin): Biguanides is an important anti-diabetic drug that inhibits hepatic gluconeogenesis, thereby reducing hyperglycemia. It has also been shown to decrease hyperlipidemia [95]. The role of metformin on bone structure and function has been a matter of controversy [102], but the most recent studies have clearly indicated that metformin may indeed have a positive role in bone health because it increases the serum concentration of alkaline phosphatase (ALP) and stimulate osteocalcin expression [103]. This indicates that metformin, a first-line therapeutic drug for DM, is safe for diabetic patients with osteoporosis. The putative beneficial effect of metformin may lie on its ability to reduce hyperglycemia, thereby reducing oxidative stress. In spite of the beneficial effect of metformin on bone architecture, some studies have indicated that metformin has adverse effect on bone. In a study comprising of 67 adult patients with type $2 \mathrm{DM}$, a significant decrease in spine and hip BMD was observed, one year after receiving metformin. The number of patients in this cohort appears to be small and the findings contradicts the findings of most reports in the literature on the effect of metformin on skeletal bone [104]. Most reports conclude that metformin has no harmful effect on bone metabolism [97]. Moreover, it has been shown that metformin stimulates osteocalcin, a hormone secreted by osteoblasts, capable of stimulating the proliferation of osteoblasts (an autocrine effect) and project a beneficial effect on glucose metabolism [67]. Table 4.

3.3.4. Meglitinides, developed by Novo Nordisk in 1997 acts on ATP-dependent potassium channels on pancreatic beta cell membrane to induce insulin release [95]. The effect of meglitinides is similar to those of sulfonylureas, albeit with a lesser likelihood of hypoglycemic episodes. Little information is available regarding the effect of meglitinides on bone health. Studies performed on rodents showed that repaglinide did not inhibit nor impair osteogenesis in 
developing embryo [105]. Since meglinitides stimulate insulin secretion, the action of this class of diabetic drugs would most likely be via insulin as it is for sulfonylureas. In contrast to the putative beneficial effects of some meglinitides, increased bone fracture risk was observed when repaglinide was used in the treatment of elderly patients aged between $65-74$ years, and in particular when combined with TZDs [106]. However, no bone fracture was observed when repaglinide was used in combination with TZDs for a relatively short duration [107].

\subsubsection{Thiazolidinediones (TZDs) stimulate PPAR- $\gamma$ to enhance the sensitivity of skeletal muscle} cells and adipocytes to insulin [108]. Several experimental [109] as well as clinical [110] studies have demonstrated that TZDs have adverse effects on bone health because they inhibit osteogenesis and stimulate apoptotic destruction of osteocytes. These observations would suggest prudence in the use of TZDs for the management of diabetic patients at risk of osteoporosis. A recent study involving 2.89 million participants, Choi and co-workers [98] observed that patients taking TZDs for DM had a markedly higher risk of bone fracture when compared to control. Table 4.

3.3.6. Glucagon-like peptide (GLP)-1 agonists belongs to the incretin family. GLP-1 increases the expression of molecules ( $\alpha-1$ coll, ALP, Runx2, osteocalcin) involved in bone formation and maintenance [111]. Although, there is a lot of controversy on whether GLP-1 agonists can reduce the risk of fracture [112], it has recently been shown to significantly reduce the risk of fracture in patients with DM [113]. In spite of the beneficial effects on bone metabolism reported in laboratory studies, several clinical studies have shown that GLP-1 agonists have no effect on $\mathrm{BMD}$, and markers of bone turnover. The role of exenatide on risks of bone fracture has been 
inconsistent with some reporting an ambivalent effect, while others reported an increase in bone fracture risk [97]. Table 4.

3.3.7. Dipeptidyl peptidase 4 (DPP-4), an ubiquitous enzyme, located on the plasma membrane of osteoblast, osteoclast and osteocyte, has been implicated in the regulation of collagen synthesis [114]. The conclusion on the effect of DPP4 inhibitors on osteoporosis has not been conclusive. Some reports have indicated that vildaglitin has no effects whatsoever on bone structure and function in osteoporosis after one year of treatment [115]. In contrast, a metaanalysis of 28 clinical trials showed that DPP-4 inhibitors improve bone health [116]. Since DPP-4 inhibitors increase the pool of incretins, which has an anabolic effect of bone, it is possible that DPP-4 inhibitors, when used in the right form, dosage and duration, would promote bone health in osteoporotic patients. In fact, in a meta-analysis of 28 clinical trials involving a cohort of 11,880 patients with more than 9,000 on DPP-4 inhibitors, it was concluded that DPP-4 inhibitors could be associated with a reduced bone fracture risk [116]. The authors, however, agreed that the conclusion has to be treated carefully because of the short duration $(\sim 24$ weeks) of most of the trials. In contrast to some beneficial effect of DPP-4 on bone health, saxaglitpin reduced osteoblast number and osteocytic density in metaphyseal trabecular bone of rats [117] Overall, many reports showed that the majority of DPP-4 inhibitors have neutral and/or beneficial effects on skeletal bone. However, a large variety of effects were reported for sitagliptin and saxagliptin. For example, saxagliptin has a harmful effect on bone health [118]. Table 4. 
3.3.8. Sodium glucose co-transporter 2 (SGLT2) inhibitors include canagliflozin, dapagliflozin, empagliflozin, and a recently FDA-approved ertugliflozin. Canagliflozin has been shown to significantly reduced bone mineral density in diabetic patients. Canagliflozin also increased the rate of skeletal fractures [119]. A possible reason for this action is that SGLT2 inhibitors cause significant changes in the level of key electrolytes $\left(\mathrm{Mg}^{2+}\right.$, phosphate, $\left.\mathrm{Ca}^{2+}, \mathrm{Na}^{+}\right)[120]$ that regulate bone structure and function. In fact, animal studies showed that canagliflozin caused increases in the level of biomarkers of bone resorption probably through persistent urinary excretion of $\mathrm{Ca}^{2+}$. In contrast, data on the use of empagliflozin in over 4,000 cohort of patients did not show increased risk fracture [121]. Since SGLT2 inhibitors increase the risk of cardiovascular disease, peripheral arterial disease and lower limb amputation [97], which are also common complications of DM [28], extreme care should be taken in the prescription of SGLT2 inhibitors to diabetes-induced osteoporosis patient. Table 4.

3.3.9. Insulin, an anabolic hormone, stimulates skeletal bone formation, and prevents bone loss leading to increased BMD [122] in experimental animals. However, several clinical studies have shown that a long-term ( 5 years $)$ use of insulin significantly contribute to BMD loss in type 2 diabetic women aged approximately 56 years [123] and increases bone fracture risk [124]. A possible reason for the high risk of bone fracture in elderly patients using insulin therapy may be due to the fact that insulin can cause hypoglycemia which may predispose patients to fall and in turn fracture their bones [124] Table 4. 
Table 4: Effect of anti-diabetic drugs in osteoporosis

\begin{tabular}{|c|c|c|c|}
\hline Anti-diabetic drug & Effect on bone/osteoporosis & Safe? & Reference \\
\hline $\begin{array}{l}\text { 1. Alpha glucosidase } \\
\text { inhibitors (acarbose, } \\
\text { miglitol and voglibose) }\end{array}$ & $\begin{array}{l}\text { Effect on osteoporosis largely } \\
\text { unknown. However, its hypoglycemic } \\
\text { and incretin stimulatory effects would } \\
\text { suggest a beneficial role in the } \\
\text { treatment of osteoporosis }\end{array}$ & Most likely & $95-98$ \\
\hline $\begin{array}{l}\text { 2. Sulfonylureas (e.g. } \\
\text { glipizide) }\end{array}$ & $\begin{array}{l}\text { Preserve and maintain osteoblast } \\
\text { structure and function. May increase } \\
\text { bone fracture risk because of increased } \\
\text { sulfonylurea-induced hypoglycemia }\end{array}$ & No & \\
\hline $\begin{array}{l}\text { 3. Biguanides (e.g. } \\
\text { metformin) }\end{array}$ & $\begin{array}{l}\text { Sustain bone structure via increases in } \\
\text { osteocalcin and ALP levels }\end{array}$ & & $\begin{array}{l}95, \quad 97, \\
102-103\end{array}$ \\
\hline $\begin{array}{l}\text { 4. Meglitinides (e.g. } \\
\text { repaglinide, nateglinide } \\
\text { mitiglinide). }\end{array}$ & $\begin{array}{l}\text { Repaglinide does not impair bone } \\
\text { formation in embryo }\end{array}$ & & $\begin{array}{l}95, \quad 104- \\
105\end{array}$ \\
\hline $\begin{array}{l}\text { 5. Thiazolidinediones (e.g. } \\
\text { pioglitazone, } \\
\text { rosiglitazone) }\end{array}$ & $\begin{array}{l}\text { Inhibit osteogenesis; increase blood } \\
\text { sclerostin; cause osteocyte apoptosis }\end{array}$ & No & $\begin{array}{l}98, \quad 106- \\
110\end{array}$ \\
\hline $\begin{array}{l}\text { 6. GLP-1 receptor } \\
\text { agonists }\end{array}$ & $\begin{array}{l}\text { Increases tissue levels of } \alpha-1 \text { collagen, } \\
\text { ALP, Runx } 2 \text {, osteocalcin }\end{array}$ & Yes & $\begin{array}{l}97, \quad 111- \\
113\end{array}$ \\
\hline 7. DPP-4 inhibitors & $\begin{array}{l}\text { Saxaglitpin inhibits osteoblast } \\
\text { proliferation }\end{array}$ & $\begin{array}{l}\text { Some products } \\
\text { have neutral } \\
\text { effect; others are } \\
\text { harmful }\end{array}$ & $114-118$ \\
\hline 8. SGLT2 inhibitors & $\begin{array}{l}\text { Urinary } \mathrm{Ca}^{2+} \text { excretion is increased; } \\
\text { Canagliflozin increases fracture risk; } \\
\text { empagliflozin does not influence } \\
\text { fracture risk }\end{array}$ & Not & $119-121$ \\
\hline 9. Insulin & Controversial & No & $122-124$ \\
\hline
\end{tabular}

\section{Conclusion}

The prevalence of diabetes mellitus (DM) continues to climb to new heights because of several factors including inappropriate diet, and sedentary lifestyle coupled with physical inactivity and genetic predisposition. Osteoporosis is a major and common complication of DM that will continue to increases in prevalence as the number of DM patients and people with impaired glucose tolerance continue to grow. It is a metabolic disease that comes with severe morbidity, 
taking a toll on the quality of life of the patient, especially when it is associated with DM. Chronic hyperglycemia, oxidative stress and advanced glycated end products have all been implicated in the etiopathogenesis of DM-induced osteoporosis.

In addition to physical exercise, sunshine, and diet rich in protein, vegetable and calcium, several anabolic and anti-resorptive osteoporosis drugs have been explored with different degrees of success. Since factors (chronic hyperglycemia, oxidative stress) associated with DM are equally detrimental to bone structure and function, it is important to treat the hyperglycemia of DM.

The quality of life of diabetes-induced osteoporotic patient would greatly improve, if all of these non-therapeutic approaches are considered and hypoglycaemia-inducing anti-diabetic drugs [SGLT2 inhibitors (canagliflozin), insulin, sulfonylureas, repaglinide] are avoided or greatly reduced.

\section{Expert Opinion}

\subsection{Approach to the treatment of DM-induced osteoporosis}

DM-induced osteoporosis develops if blood glucose level is not well controlled either because of poor medication or non-compliance. Medication is not the only factor needed for the maintenance of euglycemia and good bone health. Appropriate physical exercise and vegetableand fruit-rich diet, and smoking cessation are crucial to maintaining overall good health whether in DM patient or someone suffering from osteoporosis. The ideal drug or drug combination capable of achieving $80-90 \%$ efficacy with little or no side effects is still elusive.

A possible reason for this dilemma is the fact that the prevalence of DM and osteoporosis increases with ageing. The advances in medicine and technology observed in the last 4-5 decades have significantly increased life span. These advances in medicine and technology increases life span, which in turn exposes many people to chronic diseases associated with ageing. In addition, 
DM and osteoporosis are complex, multifactorial metabolic diseases that are influenced by a myriad of factors (genetic predisposition, endogenous antioxidant pool, environmental pollutants etc.). It is well known that tissue turnover, as seen in wound healing, is slower in patients with DM, because of micro- and macroangiopathy, neuropathy, oxidative stress and deformation of body proteins by DM-induced glycation. All of these attest to the complexity of managing DMinduced osteoporosis.

Anti-osteoporosis drugs that can be safely used in a patient with DM include vitamin D, osteocalcin (experimental), bisphosphonates (maximum of 1- 2-year treatment), and RANKL antibody. Many other drugs have a neutral or adverse effect on glucose metabolism. Anti-DM drugs that can safely be used in patients with osteoporosis include GLP-1 agonists, and metformin. Other anti-DM drugs such as insulin, thiazolidinediones, SGLT2 inhibitors, DPP4 inhibitors and sulfonylureas should be used with caution (Tables 3,4 ) because of the risk of hypoglycemia, which will in turn increase the prospect of fall and bone fracture risk. Osteocalcin-stimulating agents, or perhaps osteocalcin itself and AGE inhibitors are potential medications for patients with DM-induced osteoporosis.

\subsection{Emerging treatment options for DM-induced osteoporosis}

The use of the anabolic agent, PTH in the treatment of osteoporosis has yielded remarkable results. The search for a better PTH analogue capable of stimulating osteoblast at low dose with higher efficacy may increase the pool of drugs available for the treatment of diabetes-induced osteoporosis. Examples of these endeavors point to the investigation on ostabolin- $\mathrm{C}$ and PTHrelated protein, an endogenous polypeptide capable of stimulating PTH1 receptor. Other peptides 
that could stimulate osteoblast activity without adverse effect on glucose metabolism could be useful.

The production of antibodies (e.g. RANKL antibody-Denosumab®, anti-sclerostin antibodyRomosozumab®) against specific molecules regulation key pathways in osteoblast and osteoclast function is a good way forward.

Any biological agent that can stimulate osteocalcin, a bone hormone capable of stimulating insulin sensitivity and proliferation of osteoblast could be an ideal drug for the treatment of DMinduced osteoporosis. Medications, such as metformin, capable of stimulating the release of osteocalcin or AMPK are useful in the treatment of DM-induced osteoporosis.

Prevention and/or treatment of AGE-induced glycation of proteins associated with the maintenance of bone health is a potential way of managing diabetes-induced osteoporosis since AGEs play important role in the pathogenesis of DM and osteoporosis, independent of each other. It has been shown that carnosine ( $\beta$-alanine and L-histidine dipeptide) prevents nonenzymatic glycation of free amine group and reducing sugar, a process leading to the formation of AGEs [125]. Carnosine, a naturally occurring, dipeptide antioxidant is also capable of scavenging reactive oxygen species [126] and neutralizing harmful transitional metallic ions in the cell [127]. Carnosine and other naturally occurring antioxidants (e.g. glutathione) could be potential, non-toxic agents in the prevention and treatment of DM, osteoporosis and a combination of both conditions. Drugs targeting the enzyme glyoxalase could also be useful in the prevention and treatment of AGEs-induced changes [140] leading to the development of DM and osteoporosis because glyoxalase can break down methylglyoxal, the main precursor of AGEs. A potential question that researchers could raise with this approach is that these molecules have broad targets and not specific to bone or DM. The response to this argument is 
that osteoporosis and DM are chronic, multifactorial metabolic disease that should be targeted by molecules responsible for a multiple set of complications. A proposed approach to the management of DM-induced osteoporosis is shown in figure 1.

\section{Funding}

This paper is funded by the College of Medicine and Health Sciences, United Arab Emirates University NP-18-11 and the United Arab Emirates University - College of Medicine and Health ZCHS-77-2014.

\section{Declaration of interest}

The authors have no relevant affiliations or financial involvement with any organization or entity with a financial interest in, or financial conflict with, the subject matter or materials discussed in the manuscript. This includes employment, consultancies, honoraria, stock ownership or options, expert testimony, grants or patents received or pending, or royalties.

\section{Reviewer Disclosures}

Peer reviewers on this manuscript have no relevant financial relationships or otherwise to disclose.

\section{References}

Papers of special note have been highlighted as either of interest $(\cdot)$ or of considerable interest $(\bullet)$ to readers. 
1. Adeghate E, Schattner P, Dunn E. An update on the etiology and epidemiology of diabetes mellitus. Ann NY Acad Sci. 2006; 1084: 1-29.

** A comprehensive review on the epidemiology of diabetes mellitus

2. van Bell TL, Coppieters KT, von Herrath MG. Type 1 diabetes: etiology, immunology, and therapeutic strategies. Physiol Rev. 2011; 91: 79-118.

3. Kahn SE, Hull RL, Utzschneider KM. Mechanism linking obesity to insulin resistance and type 2 diabetes. Nature 2006; 444(7121): 840-846.

4. Olokoba A B, Obateru OA, Olokoba LB. Type 2 Diabetes Mellitus: A Review of Current Trends. Oman Medical J. 2012; 27(4): 269-273.

5. Kusunoki $\mathrm{Y}$, Katsuno $\mathrm{T}$, Nakae $\mathrm{R}$, et al. Insulin resistance and $\beta$-cell function: influence postprandial blood glucose levels in Japanese patients with gestational diabetes mellitus. Gynecol Endocrinol. 2015; 31: 929-933.

6. Gilmartin ABH, Ural SH, Repke JT. Gestational Diabetes Mellitus. Rev Obstet Gynecol. 2008; 1: 129-134.

7. Jackuliak P, Payer J. Osteoporosis, Fractures, and Diabetes Int J Endocrinol. 2014; 2014: 820615 .

8. Piepkorn B, Kann P, Forst T, et al. Bone mineral density and bone metabolism in diabetes mellitus. Horm Metab Res. 1997; 29:584-591.

9. Papadakis MA, McPhee SJ, Rabow MW. Current Medical Diagnosis and Treatment 57th Edition, Lange Medical Books, New York. 2018; 1155-1156.

10. Rakic V, Davis WA, Chubb SAP, et al. Bone mineral density and its determinants in diabetes: The Fremantle Diabetes Study. Diabetologia 2006; 49: 863-871.

** Overview of the effect of diabetes mellitus on bone mineral density 
11. Nguyen TV, Sambrook PN, Eisman JA. Bone loss, physical activity, and weight change in elderly women: the Dubbo Osteoporosis Epidemiology Study. J Bone Miner Res. 1998; 13:1458-1467.

12. Marques EA, Elbejjani M, Gudnason V, et al. Cigarette smoking and hip volumetric bone mineral density and cortical volume loss in older adults: The AGES-Reykjavik study. Bone. 2018; 108:186-192.

13. Targownik LE, Lix LM, Metge CJ, et al. Use of proton pump inhibitors and risk of osteoporosis- related fractures. CMAJ 2008; 179:319-326.

14. Tian L, Yang R, Wei L, et al. Prevalence of osteoporosis and related lifestyle and metabolic factors of postmenopausal women and elderly men: A cross-sectional study in Gansu province, Northwestern of China. Medicine (Baltimore). 2017; 96(43):e8294.

15. Wadolowska L, Sobas K, Szczepanska JW, et al. Dairy products, dietary calcium and bone health: possibility of prevention of osteoporosis in women: the Polish experience. Nutrients. 2013; 5:2684-707.

16. Iwaniec UT, Turner RT. Influence of body weight on bone mass, architecture and turnover. J Endocrinol. 2016; 230:R115-30.

17. Conradie M, Conradie MM, Kidd M, et al. Bone density in black and white South African women: contribution of ethnicity, body weight and lifestyle. Arch Osteoporos. 2014; 9:193.

18. Ralston SH, Uitterlinden AG. Genetics of osteoporosis. Endocr Rev. 2010; 31:629-662. $* *$ Comprehensive review on the genetics of osteoporosis 
19. Thijssen JH. Gene polymorphisms involved in the regulation of bone quality. Gynecol Endocrinol, 2006; 22:131-139.

20. Hyeon JH, Gwak JS, Hong SW, et al. Relationship between bone mineral density and alcohol consumption in Korean men: the Fourth Korea National Health and Nutrition Examination Survey (KNHANES), 2008-2009. Asia Pac J Clin Nutr. 2016; 25:308-315.

21. International Diabetes Federation Diabetes Atlas. $8^{\text {th }}$ Edition. Chapter 3, page 40.

22. Zhang Y, Hu G, Zhang L, et al. A Novel Testing Model for Opportunistic Screening of Pre-Diabetes and Diabetes among U.S. Adults. PLoS One. 2015; 10(3): e0120382.

23. Zimmet P. Globalization, coca-colonization and the chronic disease epidemic: can the Doomsday scenario be averted? J Intern Med. 2000; 247:301-10.

24. Kanis JA. WHO Technical Report. University of Sheffield, UK: 66. 2007

25. EFFO and NOF. Who are candidates for prevention and treatment for osteoporosis? Osteoporos Int. 1997; 7:1-6.

26. Gullberg B, Johnell O, Kanis JA. Worldwide projections for hip fracture. Osteoporos Int $1997 ; 7: 407-413$.

27. International Osteoporosis Foundation. The Asian Audit: Epidemiology, costs and burden of osteoporosis in Asia 2009. 2009 www.iofbonehealth.org.

28. Lotfy M, Adeghate J, Kalasz H, et al. Chronic complications of diabetes mellitus: A Mini Review. Curr Diabetes Rev. 2017; 13: 3-10.

** A short review of diabetes complications

29. Al-Maatouq MA, El-Desouki MI, Othman SA, et al. Prevalence of osteoporosis among postmenopausal females with diabetes mellitus. Saudi Med J. 2004; 25:1423-427. 
30. Valderrábano RJ, Linares MI. Diabetes mellitus and bone health: epidemiology, etiology and implications for fracture risk stratification Clin Diabetes Endocrinol. 2018; 4: 9.

31. Gunczler P, Lanes R, Paoli M, et al. Decreased bone mineral density and bone formation markers shortly after diagnosis of clinical type 1 diabetes mellitus. J Pediatr Endocrinol Metab. 2001; 14: 525-528.

32. Ganz ML, Wintfeld N, Li Q, et al.. The association of body mass index with the risk of type 2 diabetes: a case-control study nested in an electronic health records system in the United States. Diabetology \& Metabolic syndrome. 2014; 6:50

33. Starup-Linde J, Hygum K, Langdahl BL. Skeletal Fragility in Type 2 Diabetes Mellitus. Endocrinol Metab (Seoul). 2018; 33:339-351.

34. Kolluru GK, Bir SC, Kevil CG. Endothelial dysfunction and diabetes: effects on angiogenesis, vascular remodeling, and wound healing. Int J Vasc Med, 2012; 2012:918267.

35. Hayyan M, Hashim MA, AlNashef IM. Superoxide Ion: generation and chemical implications. Chem Rev. 2016; 116: 3029-3085.

36. Saito M, Fujii K, Soshi S, et al. Reductions in degree of mineralization and enzymatic collagen cross-links and increases in glycation-induced pentosidine in the femoral neck cortex in cases of femoral neck fracture. Osteoporos Int. 2006; 17(7):986-995.

37. Li G, Xu J, Li Z. Receptor for advanced glycation end products inhibits proliferation in osteoblast through suppression of Wnt, PI3K and ERK signaling. Biochem Biophys Res Commun. 2012 Jul 13; 423:684-689. 
38. Ding KH, Wang ZZ, Hamrick MW, et al. Disordered osteoclast formation in RAGEdeficient mouse establishes an essential role for RAGE in diabetes related bone loss. Biochem Biophys Res Commun. 2006;340:1091-1097.

39. Hein GE. Glycation endproducts in osteoporosis--is there a pathophysiologic importance? Clin Chim Acta. 2006; 371(1-2): 32-36.

40. Changrani NR, Chonka A, Adeghate E, et al. Effects of streptozotocin-induced type 1 diabetes mellitus on total protein concentrations and cation contents in the isolated pancreas, parotid, submandibular, and lacrimal glands of rats. Ann N Y Acad Sci. 2006; 1084: 503-519.

41. Patel R, Shervington A, Pariente JA, et al. Mechanism of exocrine pancreatic insufficiency in streptozotocin-induced yype 1 diabetes mellitus. Ann N Y Acad Sci. 2006; 1084: 71-88.

42. Chen H, Li J, Wang Q Associations between bone-alkaline phosphatase and bone mineral density in adults with and without diabetes. Medicine (Baltimore). 2018; 97:e0432.

43. Tamura Y, Kawao N, Okada K, et al. Plasminogen activator inhibitor-1 is involved in streptozotocin-induced bone loss in female mice. Diabetes 2013; 62: 3170-3179.

44. Canecki-Varžić S, Prpić-Križevac I, Bilić-Ćurčić I. Plasminogen activator inhibitor-1 concentrations and bone mineral density in postmenopausal women with type 2 diabetes mellitus. BMC Endocr Disord. 2016; 16:14.

45. Lee NK, Sowa H, Hinoi E, et al. Endocrine regulation of energy metabolism by the skeleton. Cell 2007; 130: 456-469.

46. Johnell O, Kanis JA. An estimate of the worldwide prevalence and disability associated with osteoporotic fractures. Osteoporos Int 2006; 17:1726-1733 
47. Kanis JA, Johnell O, De Laet C, et al. A meta-analysis of previous fracture and subsequent fracture risk. Bone 2004; 35:375-382.

48. Kanis JA, Delmas P, Burckhardt P, et al. Guidelines for diagnosis and management of osteoporosis. The European Foundation for Osteoporosis and Bone Disease. Osteoporos Int 1997; 7:390-406

49. International Osteoporosis Foundation. Treating Osteoporosis. https://www.iofbonehealth.org (Accessed on October 1, 2018)

** Detailed information on several aspects of osteoporosis

50. Santos L, Elliott-Sale KJ, Sale C. Exercise and bone health across the lifespan Biogerontology. 2017; 18(6): 931-946.

$* * * *$ Excellent information on the role of exercise in Osteoporosis

51. Nair R, Maseeh A. Vitamin D: The "sunshine" vitamin. J Pharmacol Pharmacother. 2012; 3: $118-126$.

52. Schwingshackl L, Hoffmann G. Long-term effects of low-fat diets either low or high in protein on cardiovascular and metabolic risk factors: a systematic review and metaanalysis. Nutr J, 2013; 12:48.

53. Schwingshack1 L, Missbach B, König J, et al. Adherence to a Mediterranean diet and risk of diabetes: a systematic review and meta-analysis. Public Health Nutr. 2015; 18: 12921299.

54. Parker L, Shaw, CS, Banting L, et al. Acute Low-Volume High-Intensity Interval Exercise and Continuous Moderate-Intensity Exercise Elicit a Similar Improvement in 24-h Glycemic Control in Overweight and Obese Adults. Front Physiol. 2016; 7: 661. 
55. Ordooei M, Shojaoddiny-Ardekani A, Hoseinipoor SH, et al. Effect of vitamin D on HbA1c levels of children and adolescents with diabetes mellitus type 1. Minerva Pediatr. 2017; 69:391-395.

56. Tucker KL, Hannan MT, Chen H, et al. Potassium, magnesium, and fruit and vegetable intakes are associated with greater bone mineral density in elderly men and women. Am J Clin Nutr 1999; 69:727-736.

57. Tella SH, Gallagher JC. Biological agents in management of osteoporosis. Eur J Clin Pharmacol. 2014; 70: 70:1291-1301

** Overview of biological agents in the management of osteoporosis

58. Neer RM, Arnaud CD, Zanchetta JR, et al. Effect of parathyroid hormone (1-34) on fractures and bone mineral density in postmenopausal women with osteoporosis. N Engl J Med. 2001; 344:1434:441.

59. https://clinicaltrials.gov/ct2/show/NCT00787358? cond $=$ ostabolin0Trank $=1$ (assessed 31 January 2019)

60. Karras SN, Anagnostis P, Antonopoulou V, et al. The combined effect of vitamin D and parathyroid hormone concentrations on glucose homeostasis in older patients with prediabetes: A cross-sectional study. Diab Vasc Dis Res. 2018;15:150-153.

61. Nachankar A, Kotwal N, Upreti V, et al. Association of Vitamin D and Parathyroid Hormone with Insulin Sensitivity, Beta Cell Function and Gestational Diabetes in Pregnancy: A Cross-Sectional, Observational Study. Diabetes Ther. 2018; 9:2081-2090.

62. Ward LM, Rauch F. Anabolic therapy for the treatment of osteoporosis in childhood. Curr Osteoporos Rep. 2018; 16:269-276. 
63. Pitteloud N, Mootha VK, Dwyer AA, et al. Diabetes Care. 2005; 28:1636-1642.

Relationship between testosterone levels, insulin sensitivity, and mitochondrial function in men.

64. Nemeth EF, Delmar EG, Heaton WL, et al. Calcilytic compounds: potent and selective $\mathrm{Ca} 2+$ receptor antagonists that stimulate secretion of parathyroid hormone. J Pharmacol Exp Ther. 2001; 299:323-331.

65. van Bezooijen RL, ten Dijke P, Papapoulos SE, et al. SOST/sclerostin, an osteocytederived negative regulator of bone formation. Cytokine Growth Factor Rev. $2005 ; 16: 319-327$.

66. Lim SY, Bolster MB. Profile of romosozumab and its potential in the management of osteoporosis. Drug Des Devel Ther. 2017; 11: 1221-1231.

67. Kanazawa I. Interaction between bone and glucose metabolism. Endocr J. 2017; 64(11):1043-1053.

68. Khosla S, Hofbauer LC. Osteoporosis treatment: recent developments and ongoing challenges. Lancet Diabetes Endocrinol. 2017; 5: 898-907.

$* * *$ Excellent overview of osteoporosis treatment

69. Nakamura M, Nomura S, Yamakawa T, et al. Endogenous calcitonin regulates lipid and glucose metabolism in diet-induced obesity mice. Sci Rep. 2018; 8:17001.

70. Mauvais-Jarvis F, Clegg DJ, Hevener AL. The role of estrogens in control of energy balance and glucose homeostasis. Endocr Rev. 2013; 34:309-338.

71. Russell RG. Bisphosphonates: the first 40 years. Bone. 2011; 49: 2:

72. Shane E, Burr D, Abrahamsen B, et al. Atypical subtrochanteric and diaphyseal femoral fractures: second report of a task force of the American Society for Bone and Mineral Research. J Bone Miner Res. 2014; 29:1-23 
73. Toulis KA, Nirantharakumar K, Ryan R, et al. Bisphosphonates and glucose homeostasis: a population-based, retrospective cohort study. J Clin Endocrinol Metab. 2015;100:19331940

74. Yang S, Leslie WD, Morin SN, et al. Antiresorptive therapy and newly diagnosed diabetes in women: a historical cohort study. Diabetes Obes Metab. 2016;18:875-881.

75. Cummings SR, San Martin J, McClung MR, et al. Denosumab for prevention of fractures in postmenopausal women with osteoporosis. N Engl J Med. 2009; 361:756-765.

76. Kiechl S, Wittmann J, Giaccari A, et al. Blockade of receptor activator of nuclear factor$\kappa \mathrm{B}$ (RANKL) signaling improves hepatic insulin resistance and prevents development of diabetes mellitus. Nat Med. 2013;19:358-363.

77. Lasco A, Morabito N, Basile G, et al. Denosumab Inhibition of RANKL and Insulin Resistance in Postmenopausal Women with Osteoporosis. Calcif Tissue Int. 2016 ; 98:123-128.

78. https://www.businesswire.com/news/home/20160902005107/en/Merck update odanacatib-Development-Program (Assessed on 07 January 2019)

79. Tella SH, Kommalapati A, Correa R. Profile of abaloparatide and its potential in the treatment of postmenopausal osteoporosis. Cureus. 2017; 9:e1300.

80. Choi SW, Kweon SS, Lee YH, et al. 25-Hydroxyvitamin D and Parathyroid Hormone Levels Are Independently Associated with the Hemoglobin A1c Level of Korean Type 2 Diabetic Patients: The Dong-Gu Study. PLoS One. 2016 Jun 30;11(6):e0158764.

81. Pepe J, Cipriani C, Sonato C, et al. Cardiovascular manifestations of primary hyperparathyroidism: a narrative review. Eur J Endocrinol. 2017;177:R297-R308.

82. Corona G, Monami M, Rastrelli G, et al. Type 2 diabetes mellitus and testosterone: a meta-analysis study. Int J Androl. 2011; 34:528-540 
83. Rawadi G, Roman-Roman S. Wnt signalling pathway: a new target for the treatment of osteoporosis. Expert Opin Ther Targets. 2005; 9:1063-1077.

84. Feigh M, Hjuler ST, Andreassen KV et al. Oral salmon calcitonin enhances insulin action and glucose metabolism in diet-induced obese streptozotocin-diabetic rats. Eur J Pharmacol. 2014; 737:91-96.

85. Gattereau A, Bielmann P, Durivage J, et al. Effect of acute and chronic administration of calcitonin on serum glucose in patients with Paget's disease of bone. J Clin Endocrinol Metab. 1980;51: 354-357.

86. Vogel VG, Costantino JP, Wickerham DL, et al. Effects of tamoxifen ys raloxifene on the risk of developing invasive breast cancer and other disease outcomes: the NSABP Study of tamoxifen and raloxifene (STAR) P-2 trial. JAMA. 2006; 295:2727-2741.

87. Mori H, Okada Y, Kishikawa H, et al. Effects of raloxifene on lipid and bone metabolism in postmenopausal women with type 2 diabetes. J Bone Miner Metab. 2013;31:89-95.

88. Schwartz A. Bisphosphonates reduce fracture risk in postmenopausal women with diabetes: Results from FIT and HORIZON trials. Presented at: American Society for Bone and Mineral Research (ASBMR) 2015 Annual Meeting; Oct. 9-12, 2015; Abstract 1141.

89. Rodan GA, Reszka AA. Bisphosphonate mechanism of action. Curr Mol Med. 2002; 2: 571-577.

90. Russell RG, Xia Z, Dunford JE et al. Bisphosphonates: an update on mechanisms of action and how these relate to clinical efficacy. Ann N Y Acad Sci. 2007; 1117:209-257.

91. Burr DB, Liu Z, Allen MR. Duration-dependent effects of clinically relevant oral alendronate doses on cortical bone toughness in beagle dogs. Bone. 2015; 71:58-62.

92. Anonymous. Strontium ranelate discontinued. DTB 2017; 55:86.

93. Cano A, Chedraui P, Goulis DG, et al. Calcium in the prevention of postmenopausal osteoporosis: EMAS clinical guide. Maturitas 2018; 107: 7-12. 
94. Paschalisa EP, Gamsjaegera S, Hasslera N, et al. Vitamin D and calcium supplementation for three years in postmenopausal osteoporosis significantly alters bone mineral and organic matrix quality. Bone 2017; 95: 41-46

95. Adeghate E, Kalasz H, Veress G, et al. Medicinal chemistry of drugs used in diabetic cardiomyopathy. Curr Med Chem. 2010; 17: 517-551.

96. Moritoh Y, Takeuchi K, Hazama M. Chronic administration of voglibose, an alphaglucosidase inhibitor, increases active glucagon-like peptide-1 levels by increasing its secretion and decreasing dipeptidyl peptidase-4 activity in ob/ob mice. J Pharmacol Exp Ther. 2009; 329:669-676.

97. Kalaitzoglou E, Fowlkes JL, Popescu I et al. Diabetes pharmacotherapy and effects on the musculoskeletal system. Diabetes Metab Res Rev. 2018; 22:e3100.

** Overview of the effect of anti-diabetic drugs on the musculoskeletal system

98. Choi HJ, Park C, Lee YK, et al. Risk of fractures and diabetes medications: a nationwide cohort study. Osteoporos Int. 2016; 27:2709-2715.

99. Dabhi AS, Bhatt NR, Shah MJ. Voglibose: An Alpha Glucosidase Inhibitor. J Clin Diagn Res. 2013; 7: 3023-3027.

100. Ma P, Gu B, Ma J, et al. Glimepiride induces proliferation and differentiation of rat osteoblasts via the PI3-kinase/Akt pathway. Metabolism. 2010; 59: 359-366.

101. Rajpathak SN, Fu C, Brodovicz KG, et al. Sulfonylureause and risk of hip fractures among elderly men and women with type 2 diabetes. Drugs Aging. 2015; 32:321-327.

102. Adil M, Khan RA, Kalam A, et al. Effect of anti-diabetic drugs on bone metabolism: Evidence from preclinical and clinical studies. Pharmacol Rep. 2017; 69:1328-1340.

** Overview of the effect of anti-diabetic drugs on bone mineral density

103. Liu Q, Xu X, Yang Z, et al. Metformin alleviates the bone loss induced by ketogenic diet: An in vivo study in mice. Calcif Tissue Int. 2018. doi: 10.1007/s00223-018-0468-3. 
104. Dutta M, Pakhetra R, Garg M. Evaluation of bone mineral density in type 2 diabetes mellitus patients before and after treatment. Medic J, Armed Forces India. 2012; 68: 4852.

105. Viertel B, Güttner J. Effects of the oral antidiabetic repaglinide on the reproduction of rats. Arzneimittelforschung. 2000; 50:425-440.

106. Chen HH, Horng MH, Yeh SY, et al. Glycemic control with thiazolidinedione is associated with fracture of T2DM patients. PLoS One. 2015; 10: e0135530.

107. Raskin P, Jovanovic L, Berger S, et al. Repaglinide/troglitazone combination therapy: improved glycemic control in type 2 diabetes. Diab Care. 2000; 23:979-983.

108. Adeghate E, Adem A, Hasan MY, et al. Medicinal Chemistry and actions of dual and pan PPAR modulators. Open Med Chem J. 2011; 5: 93-98.

109. Shockley KR, Lazarenko OP, Czernik PJ, et al. PPARgamma2 nuclear receptor controls multiple regulatory pathways of osteoblast differentiation from marrow mesenchymal stem cells. J Cell Biochem. 2009; 106: 232-246.

110. Schwartz AV, Sellmeyer DE. Thiazolidinediones: new evidence of bone loss. J Clin Endocrinol Metab. 2007; 92:1232-1234.

111. Ma X, Meng J, Jia M, et al. Exendin-4, a glucagon-like peptide-1 receptor agonist, prevents osteopenia by promoting bone formation and suppressing bone resorption in aged ovariectomized rats. J Bone Miner Res. 2013; 28:1641-1652.

112. Su B, Sheng H, Zhang M, et al. Risk of bone fractures associated with glucagon-like peptide-1 receptor agonists' treatment: a meta-analysis of randomized controlled trials. Endocrine 2015; 48:107-115.

113. Mabilleau G, Mieczkowska A, Irwin N, et al. Beneficial effects of a N-terminally modified GIP agonist on tissue-level bone material properties. Bone. 2014; 63:61-68. 
114. Carbone LD, Bůžková P, Fink HA, et al. Association of DPP-4 activity with BMD, body composition, and incident hip fracture: the Cardiovascular Health Study. Osteoporos Int. $2017 ; 28: 1631-1640$.

115. Bunck MC, Poelma M, Eekhoff EM, et al. Effects of vildagliptin on postprandial markers of bone resorption and calcium homeostasis in recently diagnosed, well-controlled type 2 diabetes patients. J Diabetes 2012; 4:181-185.

116. Monami M, Dicembrini I, Antenore A, et al. Dipeptidyl peptidase-4 inhibitors and bone fractures: a meta-analysis of randomized clinical trials. Diabetes Care. 2011; 34: 24742476 .

117. Sbaraglini ML, Molinuevo MS, Sedlinsky C, et al. Saxagliptin affects long-bone microarchitecture and decreases the osteogenic potential of bone marrow stromal cells. Eur J Pharmacol. 2014; 727: 814.

118. Yang Y, Zhao C, Liang J, et al. Effect of dipeptidyl peptidase-4 inhibitors on bone metabolism and the possible underlying mechanisms. Front Pharmacol. 2017; 8:487.

119. Lupsa, Inzucchi SE. Use of SGLT2 inhibitors in type 2 diabetes: weighing the risks and benefits. Diabetologia. 2018; 61: 2118-2125.

120. Taylor SI, Blau JE, Rother KI. Possible adverse effects of SGLT2 inhibitors on bone. Lancet Diabetes Endocrinol. 2015; 3:8-10.

121. Kohler S, Zeller C, Iliev H, et al. Safety and tolerability of empagliflozin in patients with type 2 diabetes: pooled analysis of Phase I-III clinical trials. Adv Ther. 2017; 34:17071726.

122. Cornish J, Callon KE, Reid IR. Insulin increases histomorphometric indices of bone formation in vivo. Calcif Tissue Int. 1996; 59:492-495.

123. Ruppert K1, Cauley J, Lian Y, et al. The effect of insulin on bone mineral density among women with type 2 diabetes: a SWAN Pharmacoepidemiology study. Osteoporos Int. 2018; 29: 347-354. 
124. Schwartz AV, Hillier TA, Sellmeyer DE,et al. Older women with diabetes have a higher risk of falls: a prospective study. Diabetes Care 2002;25:1749-1754

125. Reddy VP, Garrett MR, Perry G et al. Carnosine: A versatile antioxidant and antiglycating agent. Sci Aging Knowledge Environ. 2005, 18: pe12

126. Freund MA, Chen B, Decker EA. The Inhibition of Advanced Glycation End Products by Carnosine and Other Natural Dipeptides to Reduce Diabetic and Age-Related Complications. Comp Rev Food Sci Food Safety 17(5). doi.org/10.1111/1541-4337.12376

127. Maessen DE, Stehouwer CD, Schalkwijk CG. The role of methylglyoxal and the glyoxalase system in diabetes and other age-related diseases. Clin Sci (Lond). 2015; 128 : 839-861. 
Approach to the treatment of diabetes-induced osteoporosis

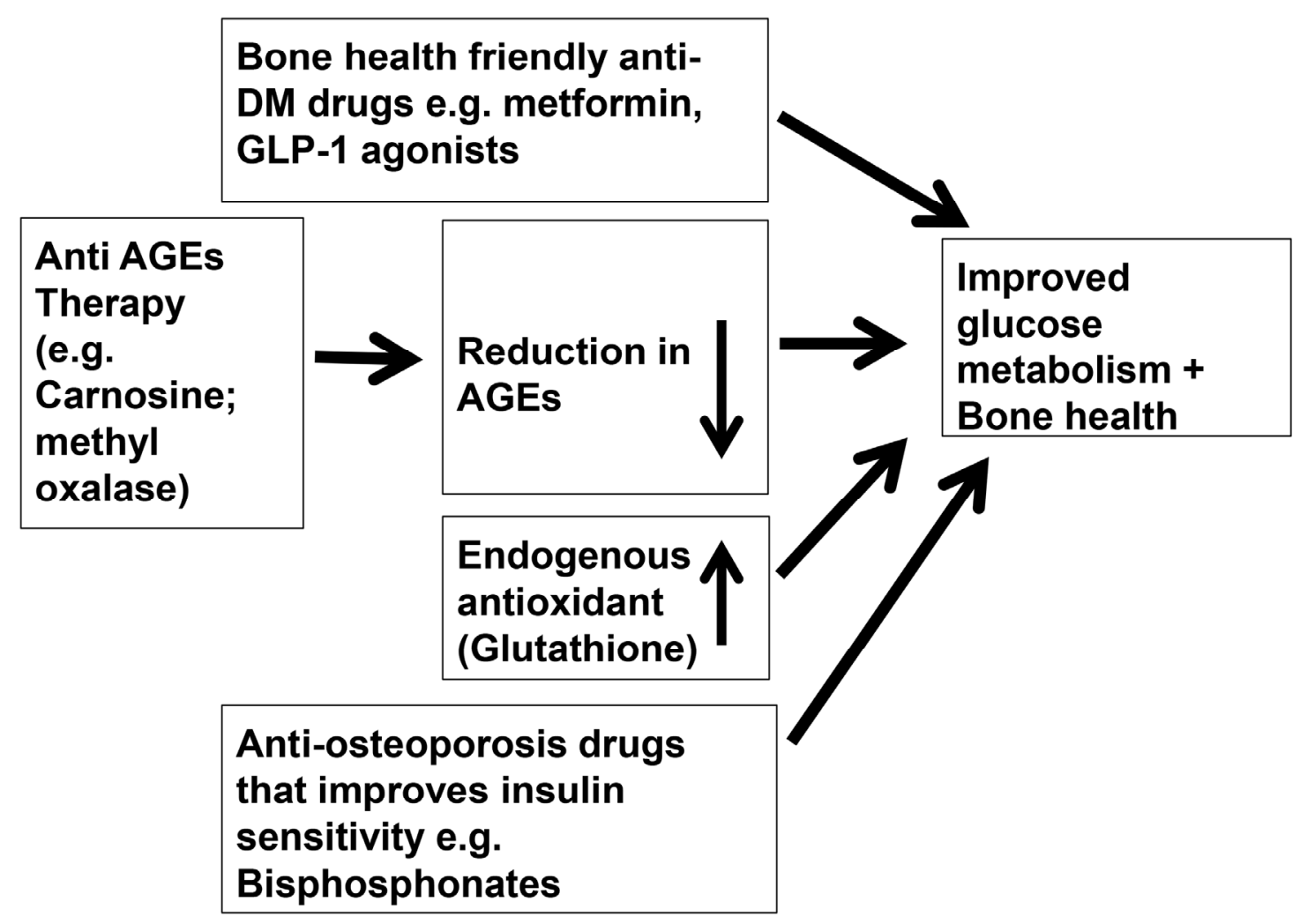

Figure 1 